Jul 1st, 12:00 AM

\title{
Implications of Complexity and Uncertainty for Integrated Modelling and Impact Assessment in River Basins
}

\author{
Valentina Krysanova \\ Fred Hattermann
}

Frank Wechsung

Follow this and additional works at: https://scholarsarchive.byu.edu/iemssconference

Krysanova, Valentina; Hattermann, Fred; and Wechsung, Frank, "Implications of Complexity and Uncertainty for Integrated Modelling and Impact Assessment in River Basins" (2004). International Congress on Environmental Modelling and Software. 16.

https://scholarsarchive.byu.edu/iemssconference/2004/all/16

This Event is brought to you for free and open access by the Civil and Environmental Engineering at BYU ScholarsArchive. It has been accepted for inclusion in International Congress on Environmental Modelling and Software by an authorized administrator of BYU ScholarsArchive. For more information, please contact scholarsarchive@byu.edu, ellen_amatangelo@byu.edu. 


\title{
Implications of Complexity and Uncertainty for Integrated Modelling and Impact Assessment in River Basins
}

\author{
Valentina Krysanova, Fred Hattermann, and Frank Wechsung
}

krysanova@pik-potsdam.de

\begin{abstract}
The paper focuses on implications of uncertainty in climate change impact assessment at the river basin and regional scales. The study was performed using the process-based ecohydrological spatially distributed model SWIM (Soil and Water Integrated Model). The model integrates hydrological processes, vegetation/crop growth, erosion and nutrient dynamics in river basins. It was developed from the SWAT and MATSALU models for climate and land use change impact assessment. The study area is the German part of the Elbe River basin (about $100.000 \mathrm{~km}^{2}$ ). It is representative for semi-humid landscapes in Europe, where water availability during the summer season is the limiting factor for plant growth and crop yield. The validation method followed the multi-scale, multi-site and multi-criteria approach and enabled to reproduce (a) water discharge and nutrient load at the river outlet along with (b) local ecohydrological processes like water table dynamics in subbasins, nutrient fluxes and vegetation growth dynamics at multiple scales and sites. The uncertainty of climate impacts was evaluated using comprehensive Monte Carlo simulation experiments.
\end{abstract}

Keywords: integrated modelling, ecohydrological model, climate impact, uncertainty, Elbe River.

\section{THE ELBE RIVER BASIN AS A CASE STUDY}

The case study area provides an example of a river basin, where the current regional trend in precipitation differs from the global trend resulting from GCMs (General Circulation Models). The study area is the German part of the Elbe River basin (about $100.000 \mathrm{~km}^{2}$ ). The long-term mean annual precipitation in the study area is $659 \mathrm{~mm}$. The long-term mean discharge of the Elbe River is $716 \mathrm{~m}^{3} \mathrm{~s}^{-1}$ at the mouth, and the specific discharge is $6.2 \mathrm{I} \mathrm{s}^{-1} \mathrm{~km}^{-2}$, which corresponds to the mean annual runoff of $10.06 \times 10^{9} \mathrm{~m}^{3}$ (29.7\% of the annual precipitation).

A primary reason for selecting this river basin as case study region is its vulnerability against water stress in dry periods. The basin is located around the boundary between the relatively wet maritime climate in western Europe and the more continental climate in eastern Europe with longer dry periods, and the annual long-term average precipitation in the area is relatively small. Therefore the Elbe
River basin is classified as the driest among the five largest river basins in Germany (Rhine, Danube, Elbe, Weser and Ems) with all resulting problems and conflicts. The region is representative of semi-humid landscapes in Europe, where water availability during the summer season is the limiting factor for plant growth and crop yield. The basin is densely populated, and has the second lowest water availability per capita within Europe. Due to expected change in circulation pattern and local orographical conditions the amount of precipitation will most likely decrease in the Elbe drainage basin (Werner \& Gerstengarbe, 1997).

\section{MODEL SWIM}

The process-based ecohydrological model SWIM (Soil and Water Integrated Model) (Krysanova et $a l ., 1998$ \& 2000) was used in the study. SWIM is a continuous-time spatially distributed model, integrating hydrological processes, vegetation growth (agricultural crops and natural vegetation), 
nutrient cycling (nitrogen, $\mathrm{N}$ and phosphorus, $\mathrm{P}$ ), and sediment transport at the river basin scale. The modelling system includes an interface to the Geographic Information System GRASS (Geographic Resources Analysis Support System) (GRASS4.1, 1993). The spatial disaggregation scheme has three levels: basin - subbasins hydrotopes. The subbasin map can be produced by using the r.watershed operation in GRASS or input from other sources, and the hydrotope map is usually produced by overlaying the subbasin, land use and soil maps. The SWIM/GRASS interface allows to extract spatially distributed parameters of elevation, land use, soil and vegetation, and to derive the hydrotope structure and the routing structure for the basin under study.

\section{MODEL VALIDATION APPROACH}

The need for powerful validation techniques for distributed hydrological and ecohydrological models has often been pointed out. While the primary idea of distributed hydrological modelling is to reproduce water fluxes in subbasins and hydrotopes along with river discharge, the models are often validated using only observed river discharge at the basin outlet, and multi-scale validation is rather exceptional. This is especially true for macro-scale basins. The river discharge is an integral attribute of hydrological processes in the river basin, but its correct representation by the model does not guarantee adequacy in spatial and temporal dynamics of all water components in the basin.

Ideally, the validation has to be multi-scale, multisite and multi-criteria and based on sensitivity and uncertainty analyses performed in advance, if the model has to be further applied at the regional scale and/or for climate or land use change impact assessment. The multi-scale and multi-site validation should include several basins of different size and located in different regions/subregions with various topographical conditions, land use composition and soils. At least some of the basins should be nested, in order to allow a special test, whether the model or some of its parameters or variables are scale-dependent.

The multi-criteria validation should include different statistical criteria of fit and spatially distributed hydrological characteristics (like soil moisture, groundwater table, snow distribution) beside commonly used Nash and Sutcliffe efficiency and water discharge at the basin outlet. Besides, an ecohydrological model must be validated also for vegetation dynamics, crop yield, nutrient fluxes in soil, nutrient load, and sediment yield.
This method of validation has been successfully applied to the model SWIM used in this study. The model was extensively validated in more than 20 subbasins (partly nested) of the Elbe River basin (Krysanova et al., 1998, Hattermann et al., 2004) using the multi-scale, multi-criteria and multi-site validation method. It has been proven that SWIM is able to reproduce satisfactory the observed river discharge, spatio-temporal groundwater table dynamics, nitrogen and phosphorus cycling in soils, nutrient loads at the basin scale, and regional crop yields. The method and its results are presented in Hattermann et al., 2004. The comprehensive model validation increases the reliability of the model, and creates a sound basis for subsequent climate impact assessment.

\section{METHODS OF CLIMATE DOWNSCALING}

Nowadays General Circulation Models (GCMs) are used for better understanding of the development of the earth climate system and prediction of future climate change. However their current resolution is too rough for correct representation of hydrological cycle variations within river catchments.

The $10 \mathrm{~km}$ resolution of climate model is a critical threshold, since at this scale the climate model outputs become comparable with the scale of variation within river catchments, and climate variables (like air temperature, precipitation) could be predicted directly without the need for downscaling. It is also important that at this scale vegetation, soil and geology can be represented explicitly without the need for upscaling. Therefore, only at this scale the climate and hydrological models could be directly linked, and the major source of uncertainty in climate impacts assessment would be removed. However, this resolution is not yet achieved in current GCMs.

The problem can be partly solved by applying downscaling methods to transform the GCM outputs into climate input parameters at the regional and river basin scale. Two main types of downscaling methods are in use: the deterministic dynamical downscaling method and the statistical downscaling method.

The deterministic models have basically the same mathematical framework as the global climate models, but a finer grid resolution. The deterministic downscaling models are applied by nesting their grid structure into the grid structure of GCMs (the outputs of GCMs are taken as boundary conditions to calculate climate input data 
for regional applications). They are physically based and can be solved numerically. The disadvantage of the deterministic downscaling models is their large data and computation demand. In addition, the physics of the atmosphere is mathematically extremely complex in such models, so that this type of models is still under development.

The second type of downscaling methods makes use of the correlation between the large-scale climate patterns (where the results of GCMs are relatively reliable) and their regional representation, considering consistency in frequency distribution, annual and inter-annual variability and persistency of the main climate characteristics. The advantage of these methods is relative robustness of their results as long as the basic climate correlations in the observed and scenario periods do not differ.

Both methods take the results of GCMs as boundary and initial conditions, and therefore the inherent uncertainty in the GCM outputs is transferred to the regional scale as well.

\section{CLIMATE CHANGE SCENARIO}

The applied climate scenario was produced in PIK (F.-W. Gerstengarbe \& P.C. Werner) by the statistical downscaling method described in Werner \& Gerstengarbe (1997) from the ECHAM4-OPYC3 GCM, which was driven by the IPCC emission scenario A1. The climate change scenario is characterized by an increase in temperature by $1.4^{\circ} \mathrm{C}$ until 2050 (Fig. 1), and a moderate decrease in mean annual precipitation (on average $-17 \%$ in the basin) corresponding to the observed regional climate trend.

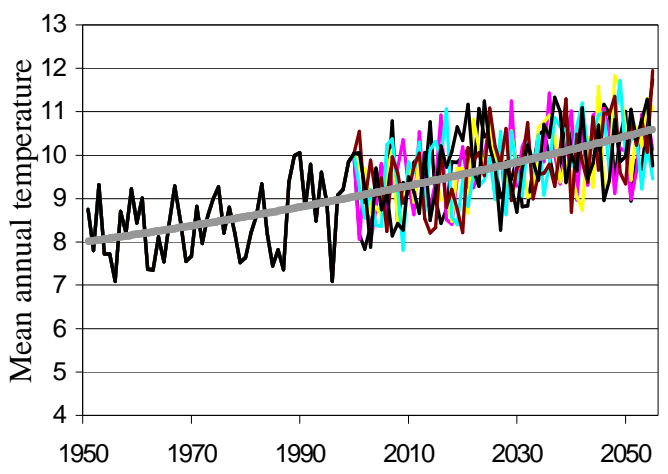

Fig. 1. The mean annual observed temperature (black line: 1950 - 1995), the mean annual temperature for six scenario realizations (1996 -
2055) for the Elbe basin. The linear trend is shown as a thick grey line

The applied statistical downscaling method maintains the stability of the main statistical characteristics (variability, frequency distribution, annual cycle, persistence). Climate scenario is developed using a special cluster analysis algorithm, which guarantees temporal, spatial and physical consistency of the considered meteorological parameters. First, the series of the reference variable (temperature) are constructed in several steps. Once the daily mean values of a long-term observed time series are obtained, it is possible to impose the assumed trend onto the series and to create the simulated series. Then the other meteorological variables are related to the reference one.

In addition, a conditioned Monte Carlo simulation was implemented in the downscaling procedure, so that 100 realizations of the scenario were produced to investigate the uncertainty of the method. Fig. 1 demonstrates the dynamics of mean annual temperature for the whole Elbe basin in the reference and scenario periods (for 6 selected scenario realizations), and the corresponding trend.

\section{CLIMATE IMPACT ASSESSMENT WITH UNCERTAINTY}

The main objective of the study was to investigate the vulnerability of water resources and agriculture in the Elbe basin against expected climate change. The crop spectrum was restricted to three major crops in the region: winter wheat, winter barley and silage maize. The adjustment of net photosynthesis and evapotranspiration to altered atmospheric $\mathrm{CO}_{2}$ concentration was studied considering two additional factors (see full description in Krysanova et al, 1999):

- adjustment of the potential growth rate per unit of intercepted PAR by a temperature dependent correction factor alpha based on experimental data for $\mathrm{C} 3$ and $\mathrm{C} 4$ crops; and

- assuming a $\mathrm{CO}_{2}$ influence on transpiration at the regional scale (factor beta), which is coupled to the direct $\mathrm{CO}_{2}$ effect of radiation use efficiency (factor alpha).

Simulation runs have been carried out in three variants: (1) only climate change without $\mathrm{CO}_{2}$ adjustment, (2) with adjustment of net photosynthesis, and (3) with adjustment of net photosynthesis and transpiration. In this way we accounted for current uncertainty regarding significance of stomatal effects on higher $\mathrm{CO}_{2}$ for 
regional evapotranspiration. Here only results related to variant (1) are discussed.

In order to evaluate the direct climate-induced uncertainty of impact assessment, the climate scenario was used along with its 100 realizations. In other words, the modelling with SWIM was used to transform the uncertainties in climate input represented by 100 realizations into ecohydrological responses like evapotranspiration, surface and subsurface runoff, river discharge, groundwater recharge, and crop yield. The model results were subsequently analyzed considering seasonal dynamics, trends, histograms for the set of 100 simulations, and spatial patterns in different sub-regions.

According to the simulation results, actual evapotranspiration is expected to decrease on average by $4 \%$, with significant subregional differences. Namely, a moderate increase up to 103 $\mathrm{mm} \mathrm{y}^{-1}$ is expected in north-western part of the basin, and a decrease up to $126 \mathrm{~mm} \mathrm{y}^{-1}$ is simulated for the loess subregion located in Saxony-Anhalt (the central part of basin). Runoff and groundwater recharge show a decreasing trend, whereas groundwater recharge responded most sensitively to the anticipated climate change $(-37 \%$ on average). Groundwater recharge decreased practically everywhere, whereas lower absolute changes are simulated in the loess area, where it is very low anyway due to soil properties.
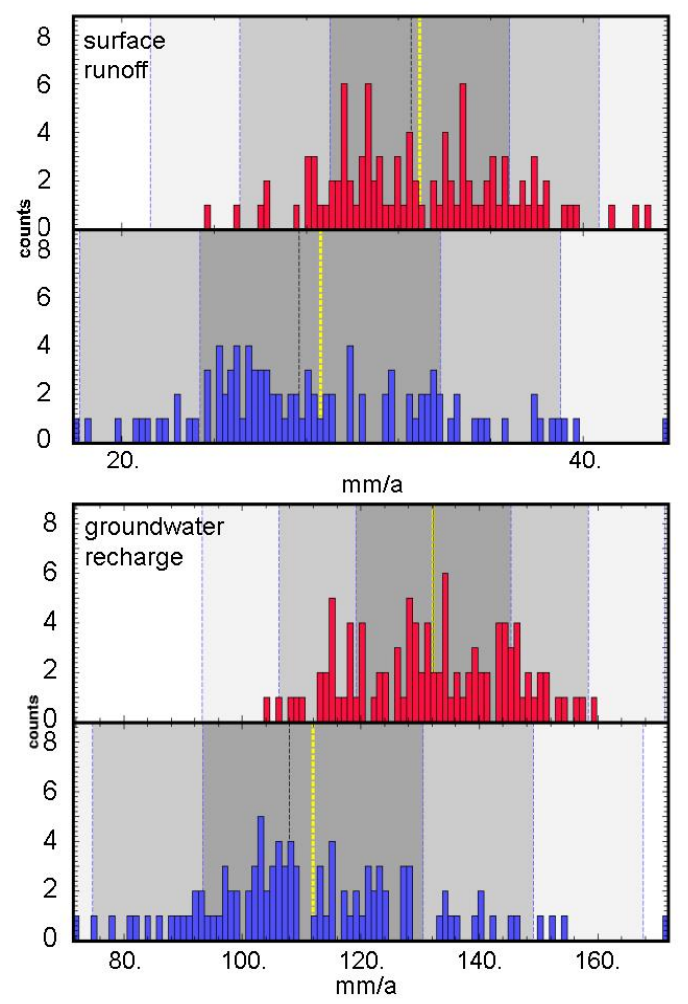

Fig. 2 Distributions of surface runoff and groundwater recharge in the Elbe basin in 20002005 (upper parts) and in 2050-2055 (lower parts) for a set of 100 climate scenario realizations

The uncertainty in hydrological response under climate change is quite high. For example, the histograms in Fig. 2 built on 100 scenario realizations compare surface runoff and groundwater recharge for the Elbe basin in 20002005 (upper parts) and in 2050-2055 (lower parts). The hydrological responses and the propagation of uncertainty differ in three main Elbe subregions: the mountainous area, the loess subregion, and the lowland area due to differences in geomorphological and climate conditions. According to the modeling results, the uncertainty in hydrological responses in lowland is higher than that in mountainous area.
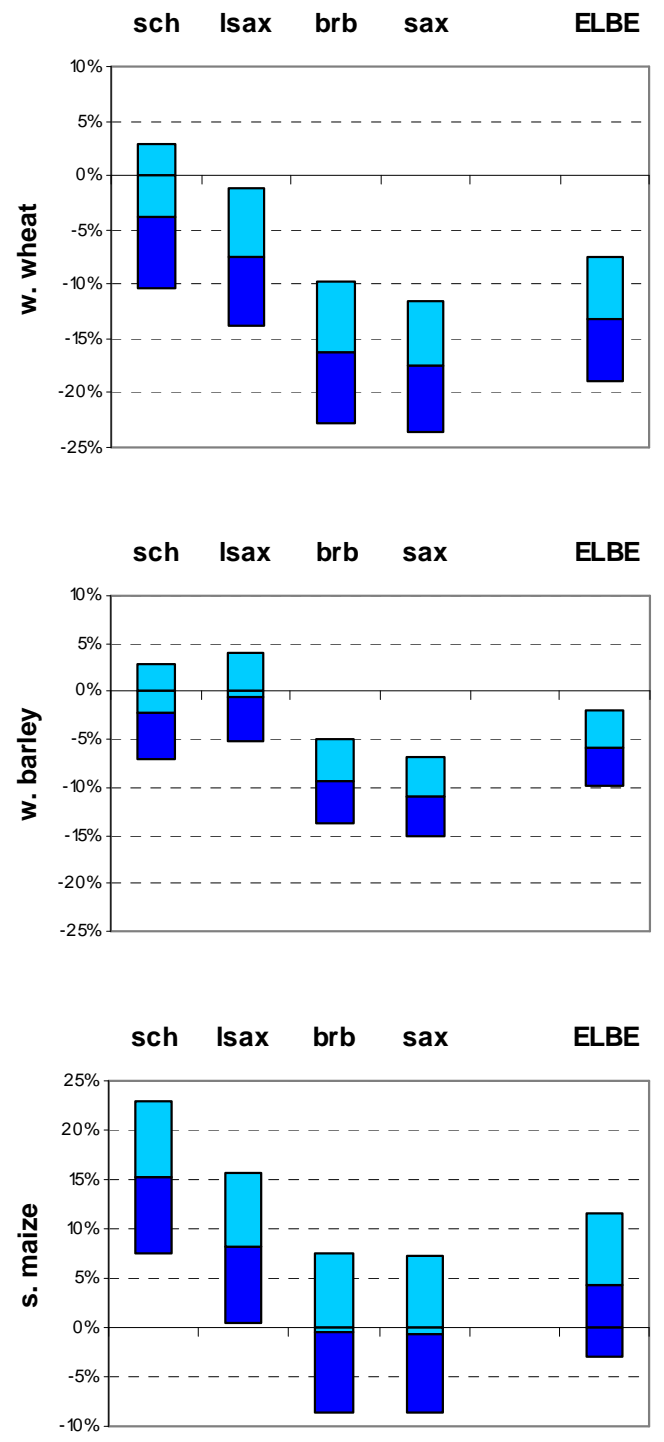

Fig. 3 Change in crop yield with the confidence intervals under climate change scenario for the 
Elbe basin and its four subregions: SchleswigHolstein (sch), Lower Saxony (lsax), Brandenburg (brb) and Saxony-Anhalt (sax) in 2046-2055 in relation to the reference period 1960-1990

The changes in crop yield (Fig. 3) were evaluated for the whole area on average, and for its four subregions: Schleswig-Holstein and Lower Saxony located in north-western part, Brandenburg located in eastern part, and Saxony-Anhalt located in the central part of the basin.

The results are depicted in Fig. 3 as changes in percent related to the reference period with the confidence interval of $95 \%$. According to the scenario, yield of winter wheat is expected to decrease in all subregions, with lowest results for Brandenburg and Saxony. Yield of winter barley would decrease rather moderately, whereas changes for Schleswig-Holstein and Lower Saxony are practically within $\pm 5 \%$ interval. For silage maize, positive response is expected in northwestern part of the basin, whereas changes in Brandenbug and Saxony-Anhalt are negligible. The confidence intervals for winter barley are the most narrow ( \pm 4 to $\pm 4.9 \%$ ), whereas they are the largest for silage maize ( \pm 7.3 to $\pm 8.1 \%)$.

\section{CONCLUSIONS}

The overall result of the study is that the mean water discharge and the mean groundwater recharge in the Elbe basin will be most likely decreased under expected climate change, but the uncertainty in hydrological response to changing climate is generally higher than the uncertainty in climate input. Crop yield is expected to decrease for cereals (winter wheat and winter barley), and moderately increase for silage maize, with significant subregional differences. A multi-criteria validation and adjustment of model parameters can reduce the uncertainty level of the model predictions. The method used in the study is transferable to other river basins.

\section{REFERENCES}

GRASS4.1. Reference Manual, US Army Corps of Engineers. Construction Engineering Research Laboatories, Champaign, Illinois, 1993.

Hattermann, F., V.Krysanova, F. Wechsung, M. Wattenbach, Multiscale and multicriterial hydrological validation of the ecohydrological model SWIM. In: A.E. Rizzoli, A.J. Jakeman (eds.), Integrated assessment and decision support. Proc. of the 1st biennial meeting of the Int. Env. Modelling and Software Society, vol. 1, 281-286, 2002.

Krysanova, V., Müller-Wohlfeil, D.I. \& Becker, A., Development and test of a spatially distributed hydrological / water quality model for mesoscale watersheds. Ecological Modelling, 106, 261-289, 1998.

Krysanova, V., Wechsung, F., Becker, A., Poschenrieder, W., Graefe, J., Mesoscale ecohydrological modelling to analyse regional effects of climate change. Environmental Modelling and Assessment, 4, 4, 259-271, 1999.

Krysanova, F. Wechsung, J. Arnold, R. Srinivasan, J. Williams, PIK Report Nr. 69 "SWIM (Soil and Water Integrated Model), User Manual", 239p., 2000.

Werner, P.C. \& F.-W. Gerstengarbe, A proposal for the development of climate scenarios. Climate Change, 8, 3, 171-182, 1997. 